\title{
Erratum to: Polyhydroxylated fatty alcohols derived \\ from avocado suppress inflammatory response and provide non-sunscreen protection against $\mathrm{UV}$-induced damage in skin cells
}

Gennady Rosenblat · Shai Meretski · Joseph Segal • Mark Tarshis • Avi Schroeder · Alexandra Zanin-Zhorov • Gilead Lion •

Arieh Ingber • Malka Hochberg

Published online: 2 March 2011

(C) Springer-Verlag 2011

Erratum to: Arch Dermatol Res

DOI 10.1007/s00403-010-1088-6

The authors would like to correct the error in the Fig. 1 carbon chain. The Carbon number in hydrocarbon chain for all five compounds in Fig. 1 should be 17 instead of 18 .

The online version of the original article can be found under doi:10.1007/s00403-010-1088-6.

G. Rosenblat $(\bowtie) \cdot$ S. Meretski · J. Segal

Polyol Biotech Ltd, Granot Initiative Center,

38100 D.N. Hefer, Israel

e-mail: gr.polyol@gmail.com

M. Tarshis

School of Medicine, Hebrew University,

91120 Jerusalem, Israel

Present Address:

A. Schroeder

Koch Institute of Integrative Cancer Research,

Massachusetts Institute of Technology,

Cambridge, MA 02142, USA

Present Address:

A. Zanin-Zhorov

School of Medicine, New York University,

New York, NY 10016, USA

G. Lion · A. Ingber · M. Hochberg

Department of Dermatology,

Hebrew University-Hadassah Medical Center,

91120 Jerusalem, Israel 